\title{
Simple way to optimise ultrasonographic visualisation of the retinal periphery and anterior segment structures
}

\author{
Amar Pujari, ${ }^{1}$ Deepa R Swamy, ${ }^{2}$ Rohan Chawla, ${ }^{2}$ Sabin Dhakal ${ }^{2}$
}

${ }^{1}$ All India Institute of Medical Sciences, New Delhi, Dr. Rajendra Prasad Centre for Ophthalmic Sciences, New Delhi, India

${ }^{2}$ Department of

Ophthalmology, Dr. Rajendra Prasad Centre for Ophthalmic Sciences, AllMS, New Delhi, India

\section{Correspondence to}

Dr Amar Pujari,

dramarpujari@gmail.com

Accepted 5 February 2017

\section{DESCRIPTION}

The ocular ultrasonography has evolved over years; the combined mode using A-scan and B-scan is very useful in the diagnosis of posterior segment pathology. Brightness mode helps in better evaluation of the mass lesion regarding their size, shape, extent and relationship with the remaining posterior segment structures. The frequency used for ophthalmic diagnosis is $8-10 \mathrm{MHz}$. The eyeball mainly encompasses the three coats: the sclera, choroid and retina. On B-scan, the normal spikes correspond to anterior lens capsule, posterior capsule, hypoechoic vitreous followed by the first high spike of the retina followed by the sclera. The retrobulbar fat is echogenic, and between this, the optic nerve can be seen as a tube-like hypoechoic channel extending from the sclera posteriorly towards the apex. ${ }^{12}$

Usual ocular scanning probe positions are transverse scan (gives the lateral extent of the lesion), longitudinal scan (gives the anteroposterior extent of the lesion) and the axial scan (demonstrates the lesion with respect to the lens and optic nerve). From the above examination methods, we are able
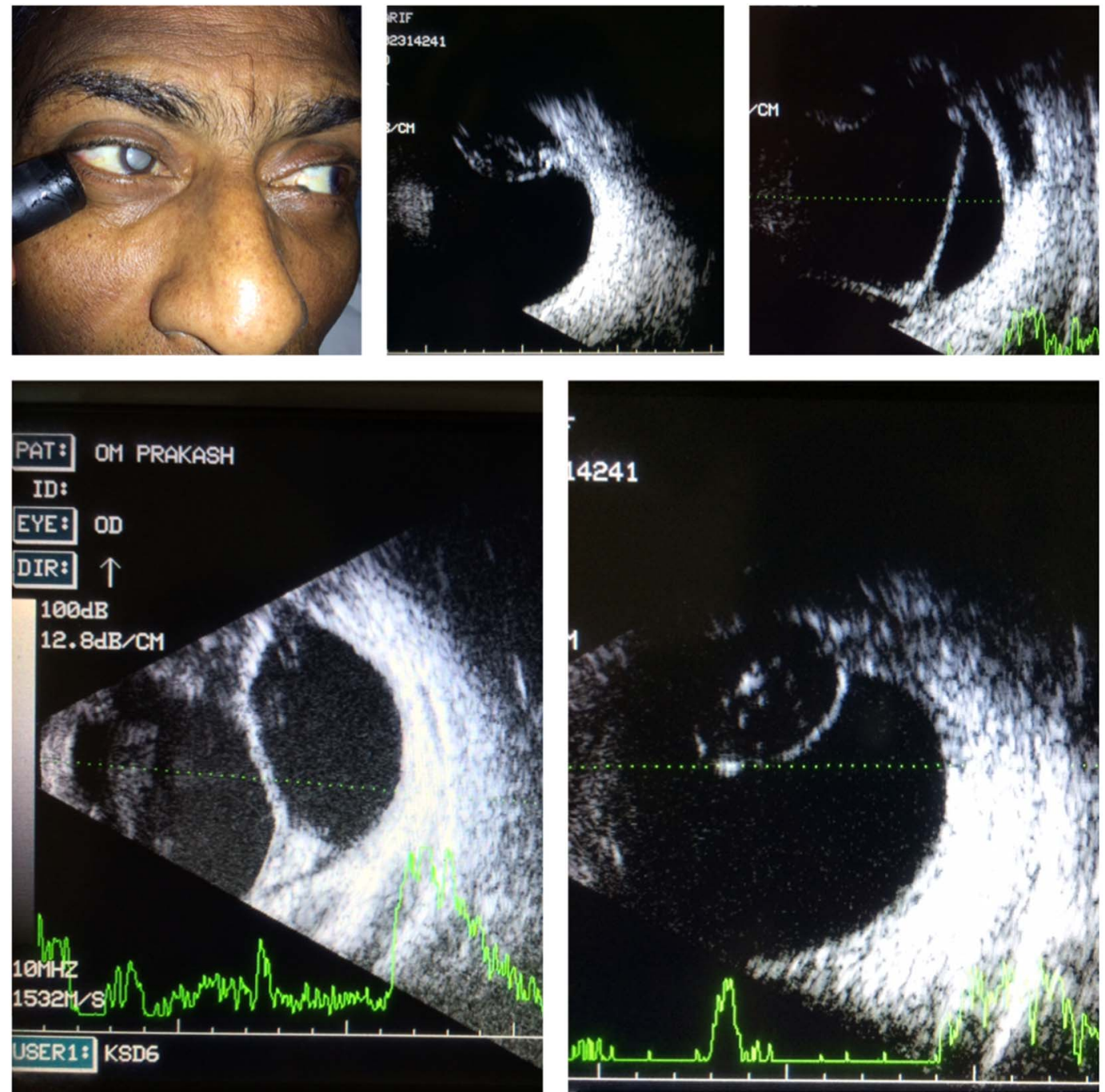

Figure 1 (A) Eye positioning and placement of the probe. (B) Normal anterior segment visualisation showing lens in its entirety, ora serrata, angle and some part of the cornea. (C) Wide funnel retinal detachment extending from the disc until the ora serrata. (D) Persistent hyperplastic primary vitreous. (E) Partially zonular attachment of the lens in a post-traumatic case. 
to screen the majority of the posterior segment structures, but visualisation of the far retinal peripheral structures of the eye is difficult. Some use the water bath technique to assess the lens status. Here, we discuss the easy way for the assessment of far peripheral retina, ora serrata, ciliary body, iris, anterior and posterior lens capsule and lens in total, angle and some part of the cornea. This examination technique involves fixation of the gaze in extreme adduction or adduction with elevation followed by placement of the probe along the lateral longitudinal plane from 6 to 9 clock hour, to assess the above-mentioned structures on

\section{Learning points}

- Better visualisation of the nasal far retinal periphery, lens, iris, angle and some part of the cornea can be achieved by this simple manoeuvre.

- It requires proper positioning of the probe in the lateral longitudinal position with the eye in extreme adduction/ adduction with elevation.

- It is easy to perform which can be performed in all routine patients who are undergoing a posterior segment ultrasound examination. the nasal half of the eyeball (figure 1A). Some of the relevant clinical findings from this technique include, (1) clear delineation of the nasal peripheral retina, the lens in its entirety, iris the superior and inferior aspect, anterior chamber, angle and partial cornea in a normal eye (figure 1B), (2) retinal detachment and persistent hyperplastic primary vitreous entirety are seen in its entire extent from the optic disc to ora and posterior surface of the lens (figure 1C,D), (3) post-traumatic posteriorly dislocated the whole lens with a partial zonular attachment on the one side (figure 1E).

Contributors AP, DRS and RC have assessed the patients using ultrasonographically before confirming the procedure. SD along with all the above-mentioned authors analysed the article and wrote the report.

Competing interests None declared.

Patient consent Obtained.

Provenance and peer review Not commissioned; externally peer reviewed.

\section{REFERENCES}

1 De La Hoz Polo M, Torramilans Lluís A, Pozuelo Segura O, et al. Ocular ultrasonography focused on the posterior eye segment: what radiologists should know. Insights Imaging 2016;7:351-64.

2 Woo MY, Hecht N, Hurley B, et al. Test characteristics of point-of-care ultrasonography for the diagnosis of acute posterior ocular pathology. Can J Ophthalmol 2016;51:336-41.

Copyright 2017 BMJ Publishing Group. All rights reserved. For permission to reuse any of this content visit http://group.bmj.com/group/rights-licensing/permissions.

BMJ Case Report Fellows may re-use this article for personal use and teaching without any further permission.

Become a Fellow of BMJ Case Reports today and you can:

- Submit as many cases as you like

- Enjoy fast sympathetic peer review and rapid publication of accepted articles

- Access all the published articles

- Re-use any of the published material for personal use and teaching without further permission

For information on Institutional Fellowships contact consortiasales@bmjgroup.com

Visit casereports.bmj.com for more articles like this and to become a Fellow 